\title{
Integrated Green Conceptions into Applied Science Course Assessing Taiwan Students' Learning Attitude and Correlation Analysis
}

\author{
King-Dow $\mathrm{Su}^{1 *}$
}

${ }^{1}$ Hungkuo Delin University of Technology, TAIWAN

*Corresponding Author: su-87168@ mail.hdut.edu.tw

Citation: Su, K-D. (2022). Integrated green conceptions into applied science course assessing Taiwan students' learning attitude and correlation analysis. Interdisciplinary Journal of Environmental and Science Education, 18(1), e2264. https://doi.org/10.21601/ijese/11424

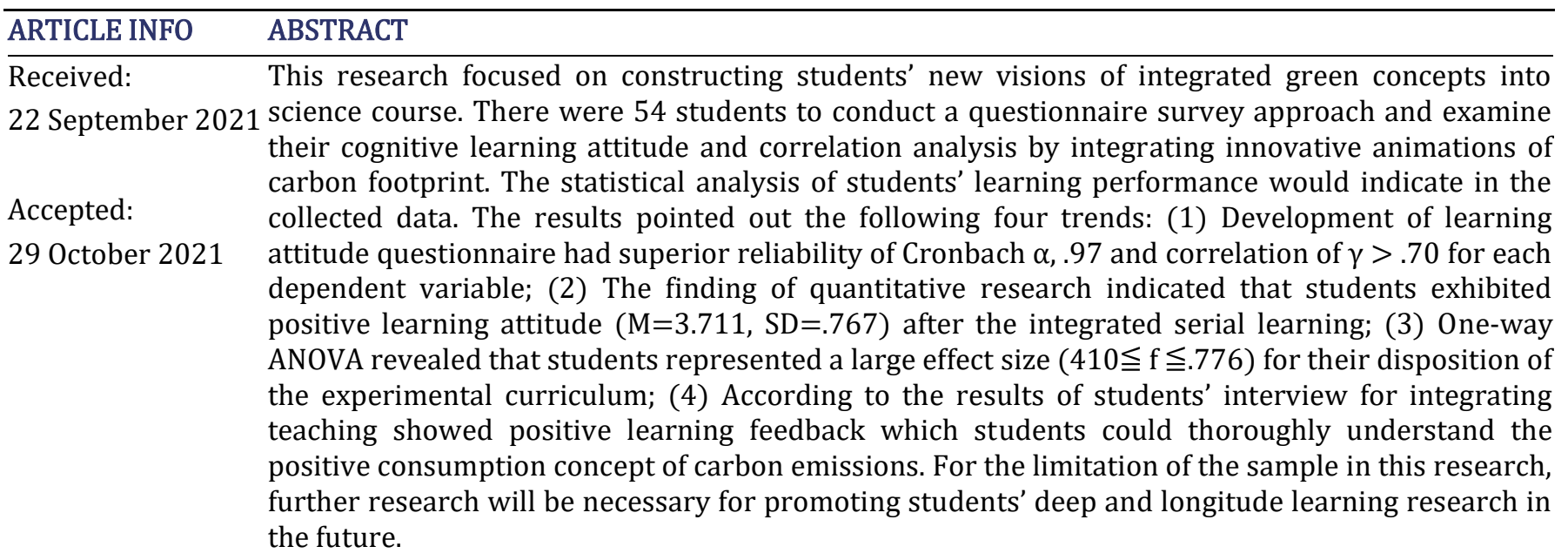

Keywords: animations, applied science course, correlation analysis, green concepts

\section{INTRODUCTION}

The essence of constructivism revealed that knowledge could construct on the minds of learners. The construction of knowledge drove students' thinking, prior knowledge, and new ideas from social and cultural backgrounds. Effectiveness problem-solving is constructed on meaningful learning strategies to assist students in reflecting and giving back in the learning process. Integrate relevant knowledge, skills, and affection so that students can interact with new concepts of life and try to construct new conceptions. Furthermore, integrated learning can drive teaching more diversification, flexibility, and effectiveness (Dawson, Forster, \& Reid, 2006), help improve students' level of thinking (Lim, 2007; Norris \& Philips, 2012), promote problem-solving skills (Lopez et al., 2014; Toledo \& Dubas, 2016), and provide instruments to develop learning performances (McFarlane \& Sakellariou, 2002). Traditional narration and teaching often result in learning difficulties due to complex learning problems to meet the learning needs of students. Therefore, multiple learning paths have become more and more urgent for students' learning. Integrating students' learning experiences will allow students to absorb knowledge effectively. Thus, innovative and creative methods are authentic behavior for their learning processes ( $\mathrm{Su}, 2021)$.

Many researchers suggested that teaching subjects not only focus on the knowledge level of the context but also enhance their understanding of reasoning process skills (Galili, 1996; Norris \& Philips, 2012). For example, the construction of an integrated learning environment with information interactive technology successfully applied to subject teaching to enhance students' learning and goal achievement (Bodemer et al., 2005; Lowe, 2003; Su, 2013). The potential benefits of creative teaching included improving subject concepts and the development of a positive learning attitude.

Copyright (C) 2022 by Author/s and Licensed by Veritas Publications Ltd., UK. This is an open access article distributed under the Creative Commons Attribution License which permits unrestricted use, distribution, and reproduction in any medium, provided the original work is properly cited. 
Interactive technology included animation, video, or other multimedia. Research scholars Olympiou, Zacharias, and deJong (2013) found that interactive technology can link the functions of numbers, graphics, and symbols, strengthen the learning concepts of the subject, and enhance the level of knowledge understanding. In the learning process, teachers play the role of mediators and provocateurs between subject learning and students. Therefore, teachers will guide students to design learning scaffolds of problem-solving and to present meaningful learning.

Based on Ausubel $(1968,2000)$ construction learning theory to set up a new strategic approach for green conception of students' visual framework. The animated presentation could be best exemplified of visual comprehensive description of Paivios' $(1971,1991)$ Dual Coding Theory and explanation of Mayer's (2009) cognitive theory of multimedia learning. Furthermore, the development of multimedia technology that combines images, animations, films, sound effects, text, and voice is now a sophisticated high-tech integration product. However, there are few animation applications in green conceptual courses to discuss learning achievement and feedback in the current literature. Therefore, this research tries to integrate carbon footprint animation into green conceptions to make teaching more helpful and learning more fun.

\section{Aims of the Study}

Based on the above description, this research focuses on the concept of a green environment, integrates it into new horizons, and practices a sustainable future. The questionnaire survey method indicated the correct learning attitude of students. The research objectives showed as follows:

1. To successfully design "carbon footprint" green animation, to integrate applied science course and to enhance students' vision and value of green concepts;

2. To observe from the classroom development of experimental teaching and understand students' learning attitude, relevance and feedback analysis in the integrated applied science course.

\section{Research Questions}

According to the above research purposes, four questions focused on students' target learning and described as follows:

1. How to successfully design green contexts and integrate applied science courses?

2. What is the reliability and validity of the learning attitude questionnaire in this research?
3. What are the students' learning differences and relevance of attitudes towards integrated applied science courses?

4. What are the students' feedback analyses about interviews after the integrated course?

\section{LITERATURE REVIEW}

\section{Cognitive Learning}

In the past two decades, constructing a cognitive learning environment for green applied in a science course, the importance of constructivism to science teaching has been valued by scientists (Trumper, 1997; Yore \& Treagust, 2006). They advocated that knowledge construction results from their thinking, prior knowledge and social and cultural backgrounds. The essence of constructivism is "Knowledge based on the learner's mind." To design teaching contexts and integrate the construction of learning environment, such as multimedia learning environment (Su, 2008; Ardac \& Akaygun, 2004), network technology integrated into curriculum learning (Own, 2006), and dynamic map integrated learning (Selvaratnam \& Canagaratna, 2008; $\mathrm{Su}, 2013$ ), which affect their motivation and interest in learning processes. At the same time, they also enhanced learning attitude and became closer for their interaction between teachers and students. In green science course, teachers can integrate proficient high-tech products, and hierarchical higher-order skills, such as image, animation, film, sound effects, text and voice multimedia technology development, and application of computer animation space capabilities. All the higher-order skills will make more and more contributions to green science education, and become more and more for their learning. Ausubel (1968) pointed that the most factor affecting is what students already know. Teachers should understand this point and cooperate with them to teach him. Su (2013) applied animation to demonstrate in class which helped students improve green literacy and problemsolving abilities. Lin and Atkinson (2011) used reminders to assist students in green conceptual learning and improved their science learning effectiveness.

Students' prior knowledge is the pursuit of learning and enlightenment for new knowledge. Teachers should examine their knowledge background and cognitive concepts before carrying out meaningful scientific knowledge transfer (Zalewska-Kurek et al., 2018). In the early stage of cognitive learning theory, students were passive knowledge receivers, and learning was knowledge acquisition. When students arrived at the maturity period, they would be more active and active, choosing relevant information to construct knowledge. Instructors will become referees and coaches for their learning, and provide learning experiences and appropriate teaching media (Su, 2014; Taber \& Coll, 2002). The most contribution of instructional design is how to apply new information, receive, and process. So that information is constantly repeated from the short- 
Table 1. Contents of green conceptions integrated into applied science course

\begin{tabular}{ll}
\hline Course & Contents \\
\hline Green Food & $\begin{array}{l}\text { life cycle, food mileage, the choice of eating is right Earth impact, transportation methods and } \\
\text { sustainable operations, against the laws of nature global food, society issues, the quality of the } \\
\text { world's well-known agricultural products, consumption smart choice, 100-mile diet, ecological } \\
\text { footprint, carbon footprint and product carbon disclosure }\end{array}$ \\
\hline
\end{tabular}

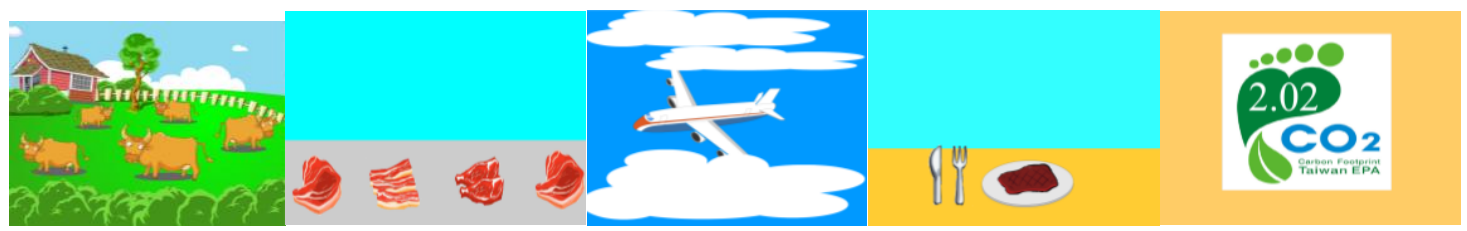

Figure 1. Summary serial animations of carbon footprint

term memory bank and gradually develops into long-term memory. That is the functionality of the cognitive learning. Therefore, constructing an environment in green catering is integrated into cognitive learning will help students learn about subject concepts.

\section{Interactive Learning in Green Course}

In recent years, scholars have used computer-assisted teaching CAI (Chang, 2003) and information interactive technology ICT ( $\mathrm{Su}, 2008)$ teaching methods, which use the concept of contextual learning to design textbooks so that students can actively control learning activities. Awareness through learning will stimulate the wisdom of students' thinking and problem-solving abilities. Under the actual situation, students actively interact with constructing the individual cognitive structure. Brown, Collins and Duguid (1989) thought that knowledge construction and skills came from the interaction between learners and situations. Then, they also stressed that knowledge understanding came from the interaction between learners and society. It assisted learners in the transfer and application of knowledge. Ardac \& Akaygun (2004) found that the integrated teaching method helped students understand abstract ideas and active learning. Su (2018) applied integrated teaching in the classroom to explore the learning effectiveness in science. The results of the study found that some are effective, and some still need to be improved. Su (2013) applied integrated teaching in the classroom to help students improve their scientific problem-solving ability.

Dual Coding Theory (DCT) emphasized the operation of memory and cognition (Paivio, 1971, 1991), and relied on the linkage between the language system and the visual system. The integration of information technology into learning of green conceptions was meaningful for the link of knowledge. To enhance their green visions and learning motivation of the students of the hospitality department. This research tried to integrate the carbon footprint animations into the green concept in the applied science course. To promote their motivation and curiosity about green science conceptions and inspire their learning interests.
Thus, students' attitude towards the integrated green concept in applied science course would make teachers' teaching more active and students' learning more meaningful.

\section{METHOD \\ Sample}

To study the appropriateness and consistency of the sampling, the sample of this study comes from 54 students (including sex distribution 18 males and 36 females; aged distribution from 20 to 22 years) who have taken the green applied science course in the hospitality department.

\section{Contents of Green Applied Science Course}

Table 1 indicates the integrated context design of the green science course. Two factors of green conceptions included carbon footprint and food mileage which combined the animated concept (shown in Figure 1) and film appreciation to enhance students' vision and value. In Figure 1, when cattle arrived in the slaughterhouse and made into beef. The airplane transported beef from the United States to Taiwan and then into consumers' stomachs. The carbon emissions were about 2.02 tons. The meaning of this animation was to convey consumers' awareness of carbon emissions and remind everyone that carbon reduction was responsible.

\section{Research Instruments}

The research instruments consisted of a learning attitude questionnaire and students' interview questionnaires. The development process would introduce as follows:

The learning attitude questionnaire adopted a Likert five-scale and provided five options, namely, from 5 (strongly agree) to 1 (strongly disagree). The first draft of this questionnaire referred to the author's ( $\mathrm{Su}, 2016$, 2018) framework and refined the questionnaire. The questionnaire has a total of 30 items. Five specialists lumped together to assess the first draft and to construct validity. Five specialists included two science educators and three science philosophers. Based on the opinions of five specialists provided revision with content and face 
validity. In terms of construct validity, the principal component analysis examined the findings of the pilot test. To extract six dimensions with Eigenvalues greater than 1.0 and their cumulative total variance bigger than $70 \%$. The specialist analysis and dimension analysis supported the claim for validity in this attitude questionnaire.

Furthermore, using Cronbach's $\alpha$ to examine the internal consistency reliability of total questionnaire and six subscales. The overall reliability $\alpha$ value is .946 for the pilot test of the learning questionnaire. The six subscales included Qa, attitude toward integrated course; $\mathrm{Qb}$, attitude toward green conceptual instructor; Qc, attitude toward multiple learning environments; Qd, attitude toward classmates; Qe, attitude toward selflearning; and Qf, attitude toward learning results.

To design a semi-structured interview questionnaire with three questions in this research. All questions consisted of the teaching goals, carbon footprint literacy and feedback of the integrated green science conceptions To examine and revised by five experts and became a formal interview questionnaire. Conducted interviews immediately after the experimental students finished the learning attitude questionnaire. Four students were randomly selected to answer three interview questions. The semi-structured questionnaire focused on understanding learning perspectives and feedback for the integrated green science course. Semi-structured questionnaire questions would describe as follows:

1. Does the integration of carbon footprint animations into green applied science course help you learning about the science concept? Why? Please illustrate with an example.

2. Does the application of carbon footprint animations integrated into the green course help your cognition ability? Why?

3. What is your overall evaluation of using carbon footprint animations to integrate into the green course? Why? Please provide an example to explain.

\section{Data Analysis}

To collect their responses for learning attitude questionnaire and feedback analyses and retained with specific English coding in the experimental teaching. To make condensing and classify the data that the author recorded all quantitative and qualitative data. The statistical methods included Cronbach's $\alpha$ internal consistency, descriptive statistical analysis, and one-way ANOVA. The covariance analysis with significant levels set at .05 to test the main effects in this research. Therefore, to conduct Schĕffè's post hoc comparisons when p-values were less than or equal to .05. SPSS for MS Windows 22.0 software performed all statistical analyses.

\section{RESULTS AND DISCUSSION}

\section{Descriptive Statistical Analysis}

After integrated teaching, all students implemented a learning attitude questionnaire. After statistical analysis, the average value of the overall subscales was 3.7, the standard deviation was .8 , and the Cronbach's $\alpha$ value was .97. The internal consistency indicated that this attitude questionnaire had higher reliability than others (Salta \& Tzougraki, 2004). However, the average value of all subscales was above 3.5 and showed that all students presented positive learning qualities. The research result echoed others reported by researchers (Adesope \& Nesbit, 2012; Lin \& Atkinson, 2011). This positive learning attitude was even more affirmation of the effectiveness of the carbon footprint animations for the green learning strategy in science course.

\section{One-way ANOVA of Learning Attitude}

All six subscales (Qa, Qb, Qc, Qd, Qe, and Qf) of the learning attitude questionnaire acted as dependent variables. Students disposition toward this science course (1. very positive, $14.9 \%, 2$. positive, $53.2 \%, 3$. neutral, $25.5 \%, 4$. negative, $6.4 \%, 5$. very negative, $0 \%$ ) performed an independent variable in this research. To use the analyses of variance were used to inspect the interesting effects of integrating course concerning their learning attitude. This research used a series of one-way ANOVA in which the attitude subscales were utilized as dependent and revealed in Table 2. In Table 2, the oneway ANOVA indicated that five subscales showed significant main effect. Students presented a nonsignificantly attitude toward multiple learning environment (Qc) $(F=2.418, p=.079, f=.410)$.

Table 2 summarized the $F$-ratios, $p$-values, and Cohen's $f$ (effect sizes, 1988) for the blocking variable of disposition toward the course. The ANOVA showed significant main effects for students' five attitude subscales, namely Qa (toward science course), Qb (toward green conceptual instructor), Qd (toward classmates), Qe (toward self-learning), and Qf (toward learning results). All five effect sizes between .599 and .776 revealed larger effect sizes (above .4). Schěffè's post hoc comparisons indicated that $\mathrm{Qa}, \mathrm{Qb}, \mathrm{Qd}, \mathrm{Qe}$, and Qf students reporting 'very positive dispositions' expressed more positive learning attitudes than those reporting 'negative dispositions', and students reporting 'positive dispositions' were more positive attitude than those reporting 'negative' ones. Schěffè's post hoc comparisons indicated Qd and Qf students reporting 'neutral dispositions' expressed more positive learning attitudes than those reporting 'negative' ones.

\section{Correlation Analysis}

The examination of the correlation coefficient $(\gamma)$ provided information on the closeness of the two 
Table 2. Summary of one-way ANOVA for learning attitude $(\mathrm{N}=54)$

\begin{tabular}{|c|c|c|c|c|c|c|c|}
\hline \multirow{2}{*}{$\begin{array}{l}\text { Blocking } \\
\text { Variable }\end{array}$} & \multirow{2}{*}{$\begin{array}{c}\text { Analysis } \\
\text { of } \\
\text { Variance }\end{array}$} & \multicolumn{6}{|c|}{ Attitude } \\
\hline & & Qa & Qb & Qc & Qd & $\mathbf{Q e}$ & Qf \\
\hline Disposition & $F$-ratio & 7.586 & 6.289 & 2.418 & 7.217 & 5.154 & 8.649 \\
\hline toward & $p$-value & $<.001$ & 0.001 & 0.079 & $<.001$ & 0.004 & $<.001$ \\
\hline Course (1.ver: & $f$ & 0.727 & 0.662 & 0.41 & 0.71 & 0.599 & 0.776 \\
\hline positive, 2 . & Schĕffè & $1>4$ & $1>4$ & & $1>4$ & $1>4$ & $1>4$ \\
\hline positive, 3 . & & $2>4$ & $2>4$ & & $2>4$ & $2>4$ & $2>4$ \\
\hline neutral, 4. & & & & & $3>4$ & & $3>4$ \\
\hline \multicolumn{8}{|l|}{ negative, 5 . } \\
\hline very negative & & & & & & & \\
\hline
\end{tabular}

variables. In this research, the correlation analyses of students' learning attitude were presented in Table 3 . In Table 3 indicated the correlation matrix analysis between six subscales of the learning attitude questionnaires. All the correlation analyses revealed a strong correlation with each other $(\gamma>$.7) (Gokhan, 2012). However, the more prominent data would illustrate as follows:

First of all, to find a high correlation between Qa (toward science course) and $\mathrm{Qb}$ (toward green conceptual instructor) in a science course. The correlation coefficient value of learning attitude, $\gamma=.936$ revealed in this study. The two variable, $\mathrm{Q} a$ and $\mathrm{Qb}$, were two relevance sub-scales. Besides, a pair of high correlation connection coefficient value of learning attitude as .922 (Qd-Qf) and .930 (Qe-Qf), the high significant correlation revealed that students toward learning results (Qf) effected classmates (Qd) and selflearning $(\mathrm{Qe})$ in this attitude questionnaire.

\section{Students' Learning Feedback}

Qualitative analysis results of semi-structured interviews presented students' contributions and thinking for green conceptions in science. This study designed a semistructured interview questionnaire to assess their learning feedback. After the teaching experiment, four students (Coding from ST1 to ST4) were randomly selected for interview to collect qualitative data. Students' interview results would describe as follows:

Q1: Does the integration of carbon footprint animations into science course help you learn about green concept? Why? Please illustrate with an example.
ST1: The integrated science course with animations of carbon footprint would be interesting for me. This green concept helped my understanding for carbon emission and consumption of food in life.

ST2: I affirmed that the teacher was attentive for the integrated science course on carbon footprint, but the content of this green concept was relatively unfamiliar for me. I expected that instructor could design more interested and brand-new green animations to enlighten students' innovative thoughts in future learning.

Q2: Do the carbon footprint animations integrated into green science course help you enhance your arithmetic calculation ability? Why? Please propose an example to state your thoughts.

ST3: Integrating green animations into the science course let me know the life cycle of each step in the food journey so I could figure out the carbon emissions and calculate the carbon footprint, which was helpful to my arithmetic ability.

ST4: Because my arithmetic calculation ability was not good, I am very concerned about the carbon footprint, but the calculation of the trace carbon was still confused for my learning. I need to spend some months constructing the life cycle.

Q3: What is your overall evaluation for the carbon footprint animations to integrate the green science course? Please provide an example to explain.

Table 3. Correlation analysis of dependent variables in the learning attitude questionnaire $(\mathrm{N}=54)$

\begin{tabular}{lllllll}
\hline Correlation & Qa & Qb & Qc & Qd & Qe & Qf \\
\hline Qa & 1.000 & .936 & .754 & .873 & .883 & .894 \\
Qb & .936 & 1.000 & .770 & .833 & .837 & .868 \\
Qc & .754 & .770 & 1.000 & .831 & .735 & .784 \\
Qd & .873 & .833 & .831 & 1.000 & .870 & .922 \\
Qe & .883 & .837 & .735 & .870 & 1.000 & .930 \\
Qf & .894 & .868 & .784 & .922 & .930 & 1.000 \\
\hline
\end{tabular}




\begin{abstract}
Four students presented the same opinions for using carbon footprint animations to integrate the green science course. They thought animations could activate our learning about green conceptions and give an authentic arithmetic conception for carbon consumption. Let students have the concept of carbon emissions when they consume in life. This concept would be different from the old chimney concept, that is, the erroneous concept that only chimney emissions had a carbon footprint. Besides, it was more interesting than previous learning in this research. All students found that the content of the contexts were clear, concise and beautiful, and creatively presented carbon emissions.
\end{abstract}

\section{Observing in Class}

In addition to the above quantitative and qualitative analysis, this research also observed students learning science in the classroom, as shown in Figure 2. In Figure 2 focused on students' learning of new content and new concepts for the green course. Through group discussion and cooperative learning, students put forward their suggestions from the study list Hence, through group discussions, they could confirm and solve problems to get the correct learning concept. To construct their knowledge concepts in green science and to improve their application ability and green literacy.

In short, the feedback upgraded a distinct learning accumulation of knowledge ( $\mathrm{Su}, 2017)$ after the integrated green science course. Researchers (Barak, 2012; Lazakidou \& Retalis, 2010) proposed that students' mental cognition knowledge played a positive role of model-based reasoning for their problem-solving approach. Accordingly, improving students' engagement of tactic fulfillments in this research about integrating green animations into science would be available for their cognitive learning. They offered many benefits when students learning complex and brand-new applied science concepts. Ainsworth (2006) suggested that the DeFT (design, functions, and tasks) framework demonstrated unique learning to design animated representations, served in students' supporting learning to the functions representations, and undertook a learner interacting to the cognitive task representations. The DeFT framework was effectiveness understanding for the integrated green applied for a science course in this research.

Furthermore, many researchers (Zahorec et al., 2014; Nasr \& Soltani, 2011) proposed that the authentic dominance of learning attitude factors would make students' learning achievement more positive and assist their science subjects more interesting. In this research, many learning advantages, such as positive learning attitudes, positive interview feedback, and group discussions to establish correct problem-solving skills. These advantages were closely related to the integrated strategies and embedded in the green science course. Into functional learning activities, let students try to achieve the learning goal of problem-solving through group cooperative learning, which was a positive result of the teaching practice of this research.

\section{CONCLUSIONS AND SUGGESTIONS \\ Conclusions}

The integrated green science course revealed that students' learning effectiveness was significant and positive learning feedback. In qualitative analyses found that students' learning of the integrated science course presented positive learning motivation. Based on the above analysis results of this research, the conclusions were described as follows:

1. The attitude questionnaire was designed with high validity and internal consistency reliability.

2. Their learning attitude presented an implication for the science course.

3. In qualitative, the integrated green science course would effectively construct a high correlation coefficient between dependent variables.

4. The findings of one-way ANOVA showed that the experimental effect sizes of this course were higher

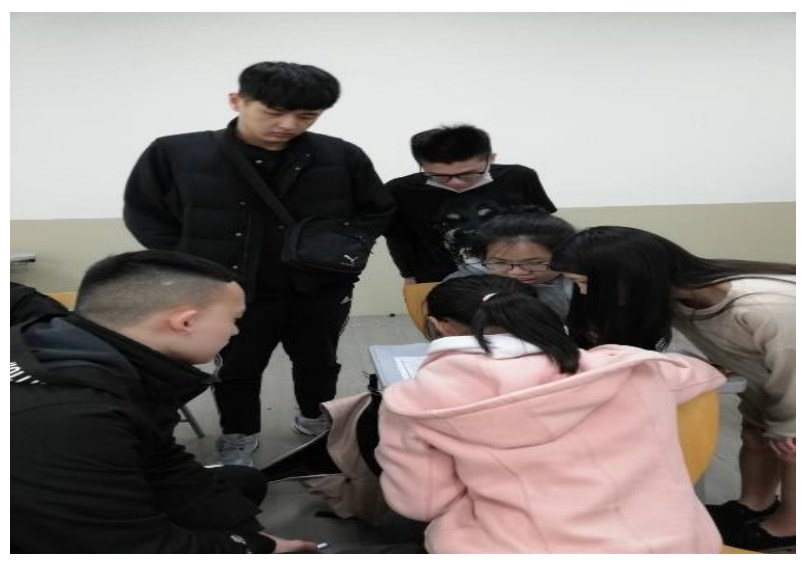

Figure 2. Students' group discusses and cooperative learning in class 
than .4 of Cohen's big one. The ANOVA revealed significant main effects for their five attitude subscales.

5. A summary for the $F$-ratios, $p$-values, and Cohen's $f$ for the blocking variable of disposition toward course. The fruitful results of integrating animations into science course was encouraging and helpful in this research.

6. Students believed that the learning content was interesting, and the content was clear, concise, and beautiful. They could thoroughly understand the positive consumption concept of carbon emissions.

\section{Suggestions}

In light of the above findings, the integrated green science courses aroused students' curiosity and interest in the green concept, changed their learning attitudes, and generated the correct concepts of green consumption. Despite this, there was still room for improvement. Therefore, this research proposed two suggestions about teaching practice and new research directions for the future requirements as follows:

1. An integrated carbon footprint animation emphasizes its easy-to-use. If it can make learners feel convenient to use, it will improve the learning efficiency even more.

2. The integration of green science concepts into courses will effectively help students establish sustainable conceptions. Due to the limited samples discussed in this research, extended inferences will make in the future. It will have to be cautious. Then, the sample increase is necessary for the future development and promotion of this research.

\section{Disclosure Statement}

No potential conflict of interest was reported by the author.

\section{REFERENCES}

Adesope, O. O., \& Nesbit, J. C. (2012). Verbal redundancy in multimedia learning environments: A meta-analysis. Journal of Educational Psychology, 104(1), 250-263.

Ainsworth, S. E. (2006). DeFT: A conceptual framework for considering learning with multiple representations. Learning and Instruction, 16(3), 183-198.

Ardac, D. \& Akaygun, S. (2004). Effectiveness of multimedia-based instruction that emphasizes molecular representations on students' understanding of chemical change. Journal of Research in Science Teaching, 41(4), 317-337.

Ausubel, D. P. (1968). Educational psychology: A cognitive view. New York: Holt, Rinehart \& Winston.

Ausubel, D.P. (2000). The acquisition and retention of knowledge: A cognitive view. Dordresht: Kluwer Academic Publishers.

Barak, M. (2012). Impacts of learning inventive problemsolving principles: Students' transition from systematic searching to heuristic problem solving. Instructional Science, 7, 1-23.

Bodemer, D., Ploetzner, R., Bruchmuller, K., \& Hacker, S. (2005). Supporting learning with interactive multimedia through active integration of representations. Instructional Science, 33, 73-95.

Brown, J.S., Collins, A., \& Duguid, P. (1989). Situated cognition and the culture of learning. Educational Researcher, 18, 32-42.

Chang, C. Y. (2003). Teaching earth sciences: Should we implement teacher-direct or student-controlled CAI in secondary classroom? International Journal of Science Education, 25, 427-438.

Cohen, J. (1988). Statistical power analysis for the behavioral sciences (2nd ed.). Hillsdale, NJ: Erlbaum.

Dawson, V., Forster, P., \& Reid, D. (2006). Information communication technology (ICT) integration a science education unit for preservice science teachers; students' perceptions of their ICT skills, knowledge and pedagogy. International Journal of Science and Mathematics Education, 4, 345-363.

Galili, I. (1996). Students' conceptual change in geometrical optics. International Journal of Science Education, 18, 847-869.

Gokhan, B. (2012). Investigating the correlation between students' perceptions on the constructivist learning environment and their academic success in science course with path analysis. Journal of Baltic Science Education, 11(4), 367-378.

Lazakidou, G., \& Retalis, S. (2010). Using computer supported collaborative learning strategies for helping students acquire self-regulated problem-solving skills in mathematics. Computers \& Education, 54(1), 3-13.

Lim, C. P. (2007). Effective integration of ICT in Singapore schools: Pedagogical and policy implications. Educational Technology Research and Development, 55, 83-116.

Lin, L., \& Atkinson, R. K. (2011). Using animations and visual cueing to support learning of scientific concepts and processes. Computers \& Education, 56, 650-658.

Lopez, E., Shavelson, R. J., Nandagopal, K., Szu, E., \& Penn, J. (2014). Factors contributing to problemsolving performance in first-semester organic chemistry. Journal of Chemical Education, 91(7), 976-981.

Lowe, R. K. (2003). Animation and learning: Selective processing of information in dynamic graphs. Learning and Instruction, 13, 157-176.

Mayer, R. E. (2009). Multimedia learning (2nd ed.). Cambridge University Press.

McFarlane, A., \& Sakellariou, S. (2002). The role of ICT in science education. Cambridge Journal of Education, $32,119-232$.

Nasr, A. R. \& Soltani, A. (2011). Attitude towards biology and its effects on student's achievement. International Journal of Biology, 3, 100-104.

Norris, S. P. \& Phillips, L. M. (2012). Reading science: How naïve view of reading hinders so much else. In A. Zohar \& Y. J. Dori (Eds.). Metacognition in science 
education: Trends in current research (pp. 37-56).

Dordrecht, The Netherlands. https://doi.org/10.1007/978-94-007-2132-6

Olympiou, G., Zacharias, Z., \& deJong, T. (2013). Making the invisible visible: Enhancing students' conceptual understanding by introducing representations of abstract objects in a simulation. Instructional Science, 41(3), 575-596.

Own, Z. (2006). The application of on adaptive web-based learning environment on oxidation-reduction reactions. International Journal of Science and Mathematics Education, 4, 73-96

Paivio, A. (1971). Imagery and verbal processes. New York, NY: Holt, Rinehart \& Winston.

Paivio, A. (1991). Dual coding theory: Retrospect and current status. Canadian Journal of Psychology, 45, 255-287.

Salta, K., \& Tzougraki, C. (2004). Attitudes toward chemistry among 11th grade students in high schools in Greece. Science Education, 88(4), 535-547.

Selvaratnam, M. \& Canagaratna, S. G. (2008). Using problem-solution maps to improve students' problemsolving skills. Journal of Chemical Education, 85, 381385.

$\mathrm{Su}$, K. D. (2008). The effects of a chemistry course with integrated information communication technologies on university students' learning and attitudes.

International Journal of Science and Mathematics Education, 6(2), 225-249.

$\mathrm{Su}$, K. D. (2013). Validity of problem-solving skills: Exploring dynamic reaction figures in acid and base chemical learning. Journal of Computer Engineering Informatics, 1(1), 1-12.

$\mathrm{Su}, \mathrm{K}$. D. (2014). Integrated molecular chemistry teaching on 12th grade students'learning performance. Research of Educational Communications and Technology, 107, $1-10$.

Su, K. D. (2016). Strengthening strategic applications of problem-solving skills for Taiwan students' chemistry understanding. Journal of Baltic Science Education, 15(6), 662-679.

$\mathrm{Su}$, K. D. (2017). Tactic fulfillments of three correlations for problem-solving maps and animated presentations to assess students' stoichiometry performances. Journal of Baltic Science Education, 16(5), 733-745.

Su, K. D. (2018). Enhancing students' corresponding reasoning of cognitive performances by animated concept mapping in electrochemistry. Journal of Baltic Science Education, 17(4), 662-673.

$\mathrm{Su}, \mathrm{K}$. D. (2021). A new assessment of HOCS-oriented learning for students' higher-order thinking abilities by Marzano's taxonomy. Journal of Baltic Science Education, 20(2), 305-315.

Taber, K. S., \& Coll, R. K. (2002). Bonding. In J. K. Gilbert, O. de Jong, R. Justi, D. F. Treagust, \& J. H. van Driel (Eds.). Chemical education: Towards researchbased practice (pp. 213-234). Dordrecht, NL: Kluwer Academic.

Toledo, S., \& Dubas, J. M. (2016). Encouraging higherorder thinking in general chemistry by scaffolding student learning using Marzano's taxonomy. Journal of Chemical Education, 93(1), 64-69. https://doi.org/10.1021/acs.jchemed.5b00184

Trumper, R. (1997). Applying conceptual conflict strategies in the learning of the energy concept. Research in Science and Technology Education, 5, 119.

Yore, L. D., \& Treagust, D. F. (2006). Current realities and future possibilities: Language and science literacyempowering research and informing instruction. International Journal of Science Education, 28, 291314.

Zalewska-Kurek, K., Egedova, K., Geurts, P. A. T. M. (2018). Knowledge transfer activities of scientists in nanotechnology. Journal of Technology Transfer, 43, $139-158$.

Zahorec, J., Haškova, A., \& Bilek, M. (2014). Impact of multimedia assisted teaching on student attitudes to science subjects. Journal of Baltic Science Education, 13, 361-380. 